\title{
Tingkat keberhasilan inseminasi buatan (IB) berdasarkan Program Sapi Induk Wajib Bunting (SIWAB) di Kecamatan Sangkub
}

\author{
J.C. Mahyun, Z. Poli*, A. Lomboan, L.R. Ngangi \\ Fakultas Peternakan Universitas Sam Ratulangi Manado, 95115 \\ *Korespondensi (corespondending author): polizulkifli@gmail.com
}

\begin{abstract}
ABSTRAK
Penelitian ini berbentuk survey dengan penjelasan (explanatory research) yaitu menjelaskan tentang keberhasilan inseminasi buatan (IB) melalui program Sapi Induk Wajib Bunting (SIWAB) di Kecamatan Sangkub Kabupaten Bolaang Mongondow Utara. Jenis data dalam penelitian ini adalah data primer dan sekunder. Pemilihan sampel responden ditentukan secara sengaja (Purposive) yaitu para peternak yang memiliki sapi betina produktif di Desa Sidodadi, Pangkusa dan Sangkub Timur sebanyak 30 responden. Teknik pengumpulan data primer ini terdiri dari beberapa cara, yaitu kuesioner, wawancara, dan observasi. Hasil penelitian menunjukan bahwa tingkat keberhasilan IB berdasarkan program SIWAB di Kecamatan Sangkub yaitu respon peternak dalam mengadopsi teknologi reproduksi IB sangat baik dengan dibuktikaan partisipasi mereka dalam mengikutsertakan ternak sapi betina produktif pada program SIWAB. Sementara itu untuk Akseptor/ternak sapi betina yang di ikutsertakan dalam program SIWAB di Kecamatan Sangkub yaitu sapi betina yang produktif berjumlah 66 ekor. Hasil pengamatan untuk service per conception terdiriatas 58 ekor satu kali pelayanan IB dan 8 ekor dua kali pelayanan dan hasil yang diperoleh adalah $1,12 \%$. Sapi yang berhasil bunting dan melahirkan berjumlah 66 ekor (100\%). Berdasarkan analisis dan hasil pembahasan, maka dapat disimpulkan secara umum bahwa respon peternak, service per conception, angka konsepsi, dan anak berhasil lahir terhadap program SIWAB di Kecamatan Sangkub berada pada kategori baik.
\end{abstract}

Kata Kunci: Sapi potong, Inseminasi buatan, Kecamatan Sangkub, Program SIWAB.

\begin{abstract}
ARTIFICIAL INSEMINATION (AI) SUCCESSFUL RATE UNDER THE MANDATORY PREGNANT CATTLE PROGRAM (SIWAB) IN SANGKUB REGENCY. This type of research is an explanatory research survey, explaining the successful rate of AI through the compulsory pregnancy cows (SIWAB) program in Sangkub District, Bolaang Mongondow Utara Regency. The purpose of the survey is to collect some data through interview measurement tools. The types of data in this study were the primary data and secondary data. Primary data were collected directly from respondents. The sample selection was determined purposively involving breeders who had productive female cows in Sidodadi, Pangkusa and East Sangkub villages as many as 30 respondents. The primary data technical application consist of several ways, including questionnaires, interviews, and observations. The results showed that the level of trust in the AI based on the SIWAB program in Sangkub Regency, mainly response of breeders to AI technology was very good with evidence of their participation in including productive cows in the SIWAB program. Whereas for acceptors / female cows participating in the SIWAB program in Sangkub Regency, mainly female cows showed 66 head productivity. For Service per Conception variable on 66 cows included in the SIWAB program produced 58 cows of one service of AI
\end{abstract}


and 8 heads of two services of AI obtaining $1.12 \%$. From the total number of cattle included in the SIWAB (IB) program in Sangkub Regency, the 66 cows were successfully pregnant and gave birth of 66 calves. Based on the analysis and results discussion, it can be concluded that generallyl the Breeder Response, Service per Conception, Conception Number, and ABL to the SIWAB program in Sangkub District were included in the good category.

Keywords: Beef cattle, artificial insemination, compulsory pregnancy cows, Sangkub district.

\section{PENDAHULUAN}

Teknologi inseminasi buatan (IB) diperkenalkan di Indonesia pada tahun lima puluhan. Kemudian mulai dilakukan ujicoba dan disosialisasikan ke daerahdaerah pada tahun 1969, namun kebijakan penerapan inseminasi buatan oleh Direktorat Jenderal Peternakan baru dimulai tahun 1976 bersamaan dengan diresmikannya sentra IB Lembang. Menurut Ismaya (2014), inseminasi buatan didefinisikan sebagai suatu proses pemasukan atau deposisi sperma atau air mani (semen) ke dalam saluran organ (alat) kelamin betina pada saat berahi (estrus) dengan menggunakan alat buatan manusia.

Kebijakan penerapan IB saat itu ditujukan untuk meningkatkan produksi dan produktivitas sapi perah dan sapi potong. Menurut Suprianto dan Djuliansah (2016) bahwa rendahnya produktivitas berdampak terhadap lambatnya populasi ternak sapi potong. Keadaan tersebut juga ditentukan oleh mutu bibit, penggunaan teknologi dan rendahnya keterampilan petani peternak. Program kegiatan IB menjadi pilihan utama dalam meningkatkan populasi dan mutu genetik ternak sapi (Rusdiana dan Praharani, 2018). Cara untuk melakukan perbaikan atau peningkatan ternak sapi potong melalui bibit yaitu dengan cara melakukan inseminasi buatan (Sudarmono dan Sugeng, 2016).

Implikasi dari penerapan IB ini adalah meningkatnya produksi dan produktivitas ternak turunannya, sekaligus dapat meningkatkan populasi. Setelah hampir empat dekade sejak IB diperkenalkan, fenomena respons masyarakat terhadap teknologi IB ini bervariasi. Fenomena tersebut secara umum dapat dikategorikan menjadi empat macam: (1) menjadi IB min-ded; (2) menerima; (3) masih mencoba-coba; dan (4) menolak (Foote, 1981; Gordon, 2004)

Pemerintah mengeluarkan rencana terbaru yakni Upaya Khusus (Upsus) Sapi Indukan Wajib Bunting atau SIWAB (Kementerian Pertanian 2019).

Kabupaten Bolaang Mongondow Utara merupakan salah satu daerah yang menerapkan program IB melalui program SIWAB dalam rangka peningkatan produktivitas dan ketersedian daging untuk menopang program pemerintah pusat mewujudkan swasembada daging 2026. Salah satunya kecamatan yang memiliki potensi pengembangan adalah Kecamatan Sangkub. Kecamatan ini memiliki populasi ternak sapi berjumlah 1.231 ekor dan terlibat dalami program pemerintah SIWAB. Berdasarkan latar belakang maka dilakukan penelitian dengan tujuan untuk mengetahui tingkat keberhasilan IB berdasarkan program SIWAB di Kecamatan Sangkub

\section{MATERI DAN METODE PENELITIAN}

Penelitian ini telah dilaksanakan pada bulan Agustus - September 2020 di Kecamatan Sangkub Kabupaten Bolaang Mongondow Utara. Penelitian ini berbentuk survey dengan penjelasan (explanatory research) yaitu menjelaskan tentang keberhasilan IB melalui program Sapi Induk Wajib Bunting (SIWAB) di 
Kecamatan Sangkub Kabupaten Bolaang Mongondow Utara.

\section{Populasi dan Sampel penelitian}

Kecamatan Sangkub terdiri dari 16 desa yaitu, Sang Tombolang, Sampiro, Sangkub I, Sangkub II, Sangkub III, Tombolango, Busisingo Induk, Pangkusa, Sidodadi, Busisingo Utara, Sangkub IV, Mokusato, Suka Makmur, Apeng Sembeka, Sangkub Timur dan Monompia. Populasi pada penelitian ini adalah peternak sapi potong di Kecamatan Sangkub. Pemilihan desa sampel ditentukan secara sengaja (purposive sampling), berdasarkan jumlah populasi sapi potong di Kecamatan Sangkub. Terpilih tiga desa yaitu pada Desa Sidodadi, Pangkusa, dan Sangkub Timur.

\section{Sumber data}

Sumber data dalam penelitian ini adalah data primer dan sekunder. Data primer adalah data yang dikumpulkan langsung dari responden. Data primer berasal dari beberapa cara, yaitu kuesioner, wawancara, dan observasi. Data primer meliputi data hasil penelitian.

Pengumpulan data dilakukan wawancara langsung ke peternak pada desa terpilih yang ada di Kecamatan Sangkub.

\section{Respon peternak pada teknologi reproduksi IB}

Hasil penelitian diperoleh bahwa respon peternak sapi di Kecamatan Sangkub dalam menerima teknologi reproduksi IB dari jumlah 30 Orang yang diwawancarai memiliki 66 ekor ternak sapi betina produktif, keseluruhan menerima dengan mengikut sertakan dalam program siwab. Hal ini menunjukan bahwa tingkat pemahaman peternak sapi di Kecamatan Sangkub sudah mengarah pada peternakan modern.

\section{Definisi Variabel}

Variabel yang diukur dalam penelitian ini adalah respon peternak pada teknologi reproduksi IB, akseptor (ternak sapi betina yang diikutsertakan dalam program SIWAB), Jumlah ternak sapi yang berhasil bunting, Service Per Conception dan jumlah ternak sapi betina dengan IB yang berhasil melahirkan hidup.

\section{Analisis Data.}

Analisis data yang digunakan dalam penelitian ini adalah analisis deskriptif. Data yang diperoleh disederhanakan ke dalam bentuk tabel kemudian dilakukan analisis deskriptif. Analisis deskriptif digunakan untuk menganalisis gambaran umum lokasi penelitian, karakteristik dan persepsi peternak terhadap program IB di Kecamatan Sangkub.

\section{HASIL DAN PEMBAHASAN}

\section{Letak, luas wilayah, jumlah penduduk}

Secara luas wilayah, Kecamatan Sangkub memiliki wilayah seluas 567,85 $\mathrm{km} 2$ atau $30,58 \%$ dari luas wilayah Kabupaten Bolaang Mongondow Utara yang juga merupakan wilayah kecamatan terluas yang ada di Kabupaten Bolaang Mongondow Utara. Kecamatan Sangkub terdiri dari 16 desa yaitu, Sang Tombolang, Sampiro, Sangkub I, Sangkub II, Sangkub III, Tombolango, Busisingo Induk, Pangkusa, Sidodadi, Busisingo Utara, Sangkub IV, Mokusato, Suka Makmur, Apeng Sembeka, Sangkub Timur dan Monompia. Berdasarkan Peraturan Daerah Kabupaten Bolaang Mongondow Utara Nomor 3 tahun 2013 tentang Rencana Tata Ruang Wilayah Kabupaten Bolaang Mongondow Utara tahun 20132033, pasal 27 ayat (6) Kecamatan Sangkub termasuk dalam kawasan peternakan yang terdiri atas ternak besar, ternak kecil, dan ternak unggas. Ternak besar meliputi sapi. Di bagian timur Kecamatan Sangkub berbatasan langsung dengan Desa Domisil Sangtombolang Kabupaten Bolaang Mongondow pintu masuk ke Bolaang Mongondow Utara, dibagian Barat bebatasan dengan desa Bintauna Pantai Kecamatan Bintauna. 


\section{Umur}

Hasil penelitian diperoleh variasi umur peternak sapi di Kecamatan Sangkub, yaitu antara 25-73 tahun. Untuk jelasnya dapat dilihat pada Tabel 1 . Berdasarkan Tabel 1. sebagian peternak/responden dengan persentase terbesar berusia antara 36-46 tahun $(37,66 \%)$ dan $25-35$ tahun $(23,33 \%)$ yang artinya usia rata-rata responden masih produktif. Tingkat umur yang demikian akan memberikan kemudahan dalam berfikir dan bertindak dengan sangat hatihati dimana dengan bertambuhnya usia maka proses berfikir seseorang dapat terpengaruh pula, semakin meningkatnya usia maka proses berfikir semakin menghasilkan suatu yang telah dipertimbangkan.

Hal ini sesuai dengan pendapat Kastalani et al. (2019) usia produktif berada dalam kisaran 30- 60 tahun. Sebaliknya, hasil penelitian Ediset dan Heriyanto (2020) menunjukkan bahwa posisi umur kurang berpengaruh dalam proses adopsi inovasi Inseminasi Buatan (IB).

\section{Tingkat Pendidikan.}

Tingkat pendidikan peternak sapi potong di Kecamatan Sangkub terdapat pada Tabel 2. Tingkat pendidikan peternak terlihat bahwa peternak responden sebagian besar lulus SD sebesar 56,66\%, SMA sebesar 26\%, SMP sebesar $10 \%$, dan S1 sebesar 6,66\%. Hal tersebut menunjukkan tingkat pendidikan masih rendah. Tingkat pendidikan berpengaruh terhadap penyerapan informasi dan pengetahuan serta cara berfikir peternak. Adopsi inovasi dan teknologi Inseminasi Buatan (IB) dipengaruhi oleh tingkat pendidikan petani peternak (Mulyawati et al., 2016). Menurut Tarmizi et al. (2018) Tingkat pendidikan peternak mempengaruhi proses belajar, semakin tinggi pendidikan seseorang semakin mudah orang tersebut untuk menerima informasi. Menerima dan memahami informasi-informasi baru, baik dari penyuluh atau inseminator, maupun dari media massa. Tingkat pendidikan peternak yang masih rendah mengakibatkan kesulitan dalam mengadopsi inovasi. Namun kesulitan tersebut dapat diatasi dengan pengalaman yang telah didapat oleh peternak dan kecakapan penyuluh saat memberikan penyuluhan (Kastalani et al., 2019) sehingga dapat dikatakan

Tabel 1. Umur Peternak Sapi Potong di Kecamatan Sangkub

\begin{tabular}{cccc}
\hline No & Umur (Tahun) & Jumlah (Orang) & Presentasi (\%) \\
\hline 1 & $25-35$ & 7 & 23,33 \\
2 & $36-45$ & 11 & 37,66 \\
3 & $46-56$ & 6 & 22,33 \\
4 & $57-67$ & 4 & 13,33 \\
5 & $68-73$ & 1 & 3,35 \\
\hline Total & & 30 & 100 \\
\hline
\end{tabular}

Tabel 2. Tingkat Pendidikan Peternak di Kecamatan Sangkub

\begin{tabular}{|c|c|c|c|}
\hline No & Tingkat Pendidikan & Jumlah (Orrang) & Presentase (\%) \\
\hline 1 & SD & 17 & 56,66 \\
\hline 2 & SMP & 3 & 10 \\
\hline 3 & SMA & 8 & 26,66 \\
\hline 4 & Perguruan Tinggi & 2 & 6,66 \\
\hline \multicolumn{2}{|r|}{ Total } & 30 & 100 \\
\hline
\end{tabular}


sumberdaya manusia (SDM) peternak masih tergolong rendah, sebab pendidikan seseorang menentukan keberhasilan dalam mengelola usaha ternaknya. Peternak atau responden yang memiliki pola pikir yang baik, dia mampu mengadopsi pengembangan informasi dan inovasi teknologi khususnya teknologi dibidang peternakan dengan cepat. Meskipun dengan pendidikan yang rendah, sikap dan pandangan peternak tentang usaha ternaknya sudah mulai maju. Belajar dari pengalaman dan pengetahuan menyebabkan kemampuan peternak untuk mengambil keputusan semakin baik dan cermat (Hifijah dan Astati, 2015).

Pendidikan juga adalah sangat berperan penting dalam proses penerimaan sosialisasi atau penyuluhan dari penyuluh tentang seberapa besar pengaruh teknologi IB dibandingkan pemeliharaan secara alamiah untuk peningkatan produktivitas/populasi ternak. Pendapat ini sesuai dengan Sutrisno dalam Novita et al. (2019) yang menyatakan tinggi rendahnya pendidikan dapat mempengaruhi kinerja pekerja. Pendapat yang sama juga disampaikan oleh peneliti sebelumnya Lamarang et al. (2017), pendidikan berpengaruh pada cara berfikir peternak yang akan melaksanakan kegiatan usaha ternaknya. Peternak yang lebih lama mendapatkan pendidikan formalnya lebih besar kemungkinan akan lebih mudah menerima atau menyerap teknologi.

\section{Pekerjaan}

Pekerjaan utama dan sampingan peternak sapi potong di Kecamatan Sangkub dapat dilihat pada Tabel 3. Tabel
3 menunjukan bahwa 96,66\% peternak sapi potong di Kecamatan Sangkub adalah sebagai pekerjaan sampingan dengan mayoritas pekerjaam utama sebagai petani dan wiraswasta, sementara itu 3,33\% peternak sapi potong di Kecamatan Sangkub, beternak sapi sebagai pekerjaan utama mereka. Hal ini menunjukan bahwa beternak dijadikan sebagai pekerjaan utama yang pastinya mampu memberikan kemajuan terhadap peternakan yang ada ditempat penelitian. Pekerjaan utama responden berkaitan langsung dengan besarnya waktu luang yang dimiliki. Tinggi rendahnya alokasi waktu pada sebuah pekerjaan dapat mempengaruhi kinerja (Novita et al. (2019).

\section{Pengalaman Beternak}

Pada Tabel 4 terlihat bahwa lama beternak menunjukan rata-rata peternak sapi potong di Kecamatan Sangkub dengan pengalaman 10-58 tahun yaitu pada ratarata $33,33 \%$, hal tersebut menggambarkan peternak sapi potong di Kecamatan Sangkub sangat berpengalaman dan cukup lama dalam mengembangkan usaha sapi potong. Purnomo et al. (2017) bahwa pengalaman dapat menjadikan peternak lebih mandiri dan terampil dalam pengelolaan usaha ternaknya. Umumnya pengalaman peternak berkorelasi positif terhadap produktivitas, dimana semakin lama pengalaman beternak maka produktivitas yang dihasilkannya pun semakin bertambah, karena semakin tinggi tingkat pengalaman beternak, maka ketrampilan dan sikap terhadap usaha ternak yang dikelolanya akan semakin baik Kastalani et al. (2019). Purnomo et al. (2017) bahwa pengalaman dapat

Tabel 3. Prioritas Pekerjaan Peternak Sapi Potong di Kecamatan Sangkub

\begin{tabular}{cccc}
\hline No & $\begin{array}{c}\text { Prioritas Pekerjaan } \\
\text { Sebagai Peternak }\end{array}$ & Jumlah (Orang) & Presentase (\%) \\
\hline 1 & Utama & 1 & 3,33 \\
2 & Sampingan & 29 & 96,66 \\
\hline & Total & 30 & 100 \\
\hline
\end{tabular}


Tabel 4 Pengalaman Peternak sapi potong di Kecamatan Sangkub

\begin{tabular}{cccc}
\hline No & Pengalaman (Tahun) & Jumlah (Orang) & Presentase (\%) \\
\hline 1 & $10-23$ & 10 & 33,33 \\
2 & $24-34$ & 10 & 33,33 \\
3 & $36-58$ & 10 & 33,33 \\
\hline \multicolumn{7}{c}{ Total } & 30 & 100 \\
\hline
\end{tabular}

menjadikan peternak lebih mandiri dan terampil dalam peternak lebih mandiri dan terampil dalam pengelolaan usaha ternaknya. Umumnya pengalaman peternak berkorelasi positif terhadap produktivitas, dimana semakin lama pengalaman beternak berkorelasi positif terhadap produktivitas, dimana semakin lama pengalaman beternak maka produktivitas yang dihasilkannya pun semakin bertambah, karena semakin tinggi tingkat pengalaman beternak, maka ketrampilan dan sikap terhadap usaha ternak yang dikelolanya akan semakin baik Kastalani et al. (2019).

\section{Akseptor}

Pada Tabel 5 terlihat dari 30 responden yang diwawancarai memiliki 66 ekor ternak sapi betina produktif dan keseluruhan diikutsertakan pada program SIWAB. Umur peternak, pengalaman beternak yang dimiliki oleh 30 responden sangat berpengaruh dalam penerapan teknologi reproduksi IB di Kecamatan Sangkub. Hal ini dibuktikan dengan partisipasi peternak dalam mengikutsertakan ternaknya pada program SIWAB. Penentuan akseptor yang produktif memiliki pengaruh yang sangat signifikan dalam keberhasilan IB pada program SIWAB dilokasi penelitian. Jika akseptor yang diikutkan pada program ini tidak dalam kategori produktif apakah dari segi umur hingga jumlah bunting dan melahirkan maka yang akan terjadi adalah kegagalan penerapan program tersebut.

\section{Service Per Conception}

Hasil penelitian menunjukan dari 66 ekor akseptor terdapat 58 ekor akseptor yang dilayani 1 kali IB berhasil bunting, sedangkan 8 ekor akseptor dilayani dengan 2 kali IB hingga berhasil bunting (Tabel 6). Dari hasil layanan IB dan akseptor yang berhasil bunting maka didapatkan Service per Conception (S/C) sebesar 1,12. Hal ini menunjukan bahwa tingkat keberhasilan IB di Kecamatan Sangkub memiliki tingkat keberhasilan yang cukup baik. Keberhasilan ini tidak lepas dari penentuan untuk memilih akseptor untuk dilayani IB harus memenuhi syarat yaitu salah satunya sudah pernah kawin hingga melahirkan. Hasil penelitian ini jauh lebih baik dibandingkan beberapa penelitian sebelumnya oleh Labetubun et al. (2014) pada sapi bali di Kabupaten Halmahera Utara Propinsi Maluku Utara S/C 1,54. Sementara itu Hasil penelitian Riyanto et al. (2015), S/C sapi potong di kecamatan Mojogedang, Jawa Tengah adalah 1,33 1,71 kali. Semakin rendah nilai tersebut, maka semakin tinggi nilai kesuburan hewan-hewan betina dalam kelompok tersebut, sebaliknya semakin tinggi nilai S/C maka akan semakin rendah nilai kesuburan kelompok betina tersebut. Menurut Saptono (2012), keberhasilan S/C tergantung tingkat kesuburan ternak jantan maupun betina, waktu inseminasi, dan teknik inseminasi yang digunakan. Pengetahuan dan keahlian tentang deteksi birahi yang dipunyai para peternak akan meningkatkan keberhasilan inseminasi. Para peternak sudah mampu dan bisa melakukan pengamatan dan pendeteksian birahi sendiri.

Nilai S/C menunjukkan tingkat kesuburan ternak. Semakin besar nilai S/C semakin rendah tingkat kesuburannya. Tingginya nilai S/C disebabkan karena 
Tabel 5. Jumlah betina produktif yang dijadikan Akseprot pada program SIWAB di Kecamatan Sangkub

\begin{tabular}{ccc}
\hline Betina Produktif (Ekor) & Akseptor (Ekor) & Presentase $(\%)$ \\
\hline 66 & 66 & 100 \\
\hline
\end{tabular}

Tabel 6. Rataan Service Per Conception sapi potong di Kecamatan Sangkub.

\begin{tabular}{ccc}
\hline Betina Bunting (Ekor) & Layanan IB & SC \\
\hline 58 & 58 & \\
8 & 16 & 1,12 \\
\hline 66 & 74 & \\
\hline
\end{tabular}

Tabel 7. Ternak sapi yang berhasil bunting hingga melahirkan dengan program SIWAB di Kecamatan Sangkub

\begin{tabular}{clc}
\hline No & \multicolumn{1}{c}{ Variabel } & Jumlah \\
\hline 1 & Sapi induk bunting & 66 \\
2 & Anak yang dilahirkan hidup & 66 \\
\hline Presentase & & $100 \%$ \\
\hline
\end{tabular}

keterlambatan peternak maupun petugas IB dalam mendeteksi birahi serta waktu yang tidak tepat untuk di IB. Keterlambatan IB menyebabkan kegagalan kebuntingan. Selain faktor manusia faktor kesuburan ternak juga sangat berpengaruh, betina keturunan bangsa exotik cenderung kesuburannya rendah bila dilakukan IB, akan tetapi akan lebih baik bila dikawinkan secara alam menggunakan pejantan pemacek (Tarmizi et al., 2018).

\section{Jumlah ternak sapi berhasil bunting dan melahirkan melalui IB}

Dari jumlah ternak sapi yang diikutkan pada program SIWAB melalui IB di Kecamatan Sangkub dengan jumlah 66 ekor, yang berhasil bunting hingga melahirkan dapat dilihat pada Tabel 7 .

Hasil penelitian menunjukan bahwa dengan jumlah 66 akseptor yang dilayani IB berhasil bunting. Penetapan akseptor bunting atau tidak adalah dengan melakukan pemeriksaan kebuntingan dengan cara palpasi rektal atau pemeriksaan dalam atau berdasarkan estrus atau tidaknya akseptor pada 3 (tiga) kali siklus estrus pasca IB (Kusrianty et al., 2016). Dari jumlah 66 akseptor yang berhasil bunting keseluruhan juga berhasil melahirkan anak hidup. Keberhasilan ini tidak terlepas dari pengamatan peternak terhadap estrus ternak sapi juga ketepatan inseminator dalam melakukan inseminasi. Jika kedua hal tersebut dalam pengamatan kurang efektif maka yang terjadi adalah kegagalan akseptor bunting bahkan sampai pada kegagalan melahirkan.

\section{KESIMPULAN}

Berdasarkan hasil pembahasan, dapat disimpulkan bahwa secara umum respon peternak, service per conception, angka konsepsi, dan anak berhasil lahir terhadap program SIWAB di Kecamatan Sangkub berada pada kategori baik

\section{Saran}

Untuk keberlanjutan perbaikan peternakan di Kecamatan Sangkub maka 
dibutuhkan perhatian penuh dan pendampingan dari Dinas terkait dan para Akademisi demi terwujudnya peternakan rakyat yang dapat menunjang program pemerintah yaitu Swasembada daging 2026

\section{DAFTAR PUSTAKA}

Dali, I., F.S. Oley, A.K. Rintjap, J.M. Tumewu. 2017. Hubungan kinerja penyuluh pertanian lapangan dengan keberhasilan peternak sapi potong di Kecamatan Kwandang Kabupaten Gorontalo Utara. Zootec 37(2): 403414.

Ediset, E. dan E. Heriyanto. 2020. Posisi status sosial ekonomi peternak sapi potong dalam proses adopsi bioteknologi reproduksi di Kabupaten Dharmasraya, Sumatera Barat. Jurnal Peternakan Indonesia. 22(1): 56-65.

Foote, R.H. 1981. Animal Industries Heavily Dependent on Reproductive Technology: The Artificial Insemination Industry In New Technologies in Animal Breeding. Editor Benjamin G. Brackett, George E. Seidel and Sarah M. Seidel. Academic Press. Pp. 13-39.

Hifijah, A. dan Astati. 2015. Analisis faktor keberhasilan inseminasi buatan ternak sapi potong di Kecamatan Tombolo Pao Kabupaten Gowa. Jurnal Tekno Sains 9(1): 1326.

Ismaya. 2014. Bioteknologi Inseminasi Buatan pada Sapi dan Kerbau. Gadjah Mada University Press. Yogyakarta

Kastalani, K., H. Torang dan A. Kurniawan 2019. Tingkat keberhasilan inseminasi buatan (IB) pada peternakan sapi potong di Kelurahan Kalampangan Kecamatan Sabangau Kota Palangka Raya. Jurnal Ilmu Hewani Tropika 8(2): 82-88.
Kusrianty, N., M. Mirajuddin dan A. Awalludin. 2016. Efektifitas inseminasi buatan pada sapi potong menggunakan semen cair. Mitra Sains 4(1): 50-57.

Labetubun, J., F. Parera. dan S. Saiya. 2014. Evaluasi pelaksanaan inseminasi buatan pada sapi bali di Kabuapaten Halmahera Utara. Jurnal Agrinimal 4(1):22-27.

Lamarang, Z, B. F. J. Sondakh, A.K. Rintjap dan A.A. Sajow, 2017. Peranan penyuluh terhadap pengambilan keputusan peternak dalam adopsi inovasi teknologi peternakan di Kecamatan Sangkub Kabupaten Bolaang Mongondow Utara. Zootec 37(2): 496-507.

Mulyawati, I.M., D. Mardiningsih dan S. Satmoko. 2016. Pengaruh umur, pendidikan, pengalaman dan jumlah ternak peternak kambing terhadap perilaku sapta usaha beternak kambing di Desa Wonosari Kecamatan Patebon. Agromedia 34(1): 85-90.

Novita, C.I., M.A.N. Abdullah, E.M. Sari dan Z. Zulfian. 2019. Evaluasi program inseminasi buatan pada sapi lokal betina di Kecamatan Juli, Kabupaten Bireuen, Provinsi Aceh. Jurnal Agripet 19(1): 31-39.

Paturochman, M. 2012. Penentuan Jumlah dan Teknik Pengambilan Sampel. Unpad Press, Bandung. 55-56

Peraturan Daerah Kabupaten Bolaang Mongondow Utara Nomor 3 Tahun 2013 tentang Rencana Tata Ruang Wilayah Kabupaten Bolaang Mongondow Utara Tahun 20132033.

Purnomo, S.H., E. T. Rahayu dan S. B. Antoro. $2017 . \quad$ Strategi pengembangan peternakan sapi potong rakyat di Kecamatan Wuryantoro Kabupaten Wonogiri. Buletin Peternakan 41(4): 484- 494.

Riyanto, J., L. Lutojo, D.M. Barcelona. 2015. Kinerja reproduksi induk sapi potong pada usaha peternakan rakyat 
di Kecamatan Mojogedang. Sains Peternakan, 13(2): 73-79.

Rusdiana, S. dan L. Praharani, 2018. Pengembangan peternakan rakyat sapi potong: kebijakan swasembada daging sapi dan kelayakan usaha ternak. Forum Penelitian Agro Ekonomi. 36(2): 97-116.

Saptono, H.S. 2012 Tingkat Kebehasilan Inseminasi Buatan Pada Sapi Perah Rakyat di Kecamatan Mojosongo Kecamatan Boyolali. Skripsi. Fakultas pertanian Universitas Sebelas Maret, Surakarta.

Suharja, A.J. 2014. Persepsi Peternak Sapi Potong Terhadap Hasil Inseminasi Buatan (IB) Menggunakan Straw Simmental. Skripsi. Program Studi Peternakan Fakultas Pertanian Universitas Majalengka.

Sudarmono, A.S dan Y.B. Sugeng. 2016. Panduan Beternak Sapi Potong. Penebar Swadaya. Jakarta.

Suprianto, S. dan D. Djuliansah. 2016. Kajian aplikasi teknologi inseminasi buatan dalam upaya peningkatan produktivitas dan pendapatan usaha ternak sapi potong di Kabupaten Tasikmalaya. Mimbar Agribisnis 1 (3): 211-225.

Tarmizi, N.B., D. Dasrul dan G. Riady. 2018. Keberhasilan Inseminasi Buatan (IB) pada Sapi Aceh Menggunakan Semen Beku Sapi Bali, Simental, dan Limosin di Kecamatan Mesjid Raya Kabupaten Aceh Besar. JIMVET, 2(3): 318328. 